\title{
THE ENHANCEMENT EFFECT OF CASTOR OIL ON THE PERMEABILITY OF FLURBIPROFEN AS TRANSDERMAL GEL
}

\author{
1MARYAM ALAAYEDI*, ${ }^{*}$ HASANAIN MAHMOOD, ${ }^{2}$ ASHTI SAEED
}

${ }^{1}$ College of Pharmacy/University of Kerbala, Kerbala, Iraq, ${ }^{2}$ College of Pharmacy/ University of Mustansiriyah, Baghdad, Iraq. Email: maryamalaayedi@gmail.com

Received: 25 Oct 2017, Revised and Accepted: 18 Dec 2017

\begin{abstract}
Objective: The object of this study was to improve flurbiprofen permeability transdermally using castor oil as penetration enhancer.

Methods: Castor oil with different concentrations (1\%, 2\%,3\%, 4\%, and 5\%) was used in this study as a natural enhancer to improve flurbiprofen permeation transdermally as a gel. The formulated gel of the drug was evaluated for several physicochemical characteristics. The in vitro release and permeability studies for the drug were performed using Franz cell diffusion apparatus across the synthetic membrane. Korsmeyer Pappas kinetic model was used to study the release mechanism of flurbiprofen from the gel.

Results: The results demonstrated that castor oil was safe with no skin irritation and the formulas were stable over time. Castor oil was significantly effective in increasing the percent of flurbiprofen permeability from $46 \% \pm 2.9$ for the gel without enhancer to $95 \% \pm 2$ for the gel with $5 \%$ castor oil and increasing its penetration is directly related to the oil concentration. Two mechanisms for the drug release from the gel were involved, which are non-Fickian (anomalous) and super case II transport.
\end{abstract}

Conclusion: Flurbiprofen gel was prepared and evaluated successfully for an in vitro parameters with a good permeation across a synthetic membrane. The results demonstrated that castor oil had an effective enhancement for permeation of flurbiprofen.

Keywords: Gel, Transdermal, Flurbiprofen, Permeability, Enhancer, Castor oil

(C) 2018 The Authors. Published by Innovare Academic Sciences Pvt Ltd. This is an open-access article under the CC BY license (http://creativecommons.org/licenses/by/4.0/) DOI: http://dx.doi.org/10.22159/ijap.2018v10i1.23348

\section{INTRODUCTION}

Transdermal delivery is a route of administration where active ingredients are delivered across the skin for systemic distribution. The administration of drugs through the skin has benefits in comparison with oral administration. It is a non-invasive administration and suitable for people who cannot administer drugs orally (unconscious or suffering vomiting). Also, gastrointestinal side effects and the first-pass metabolism can be avoided [1-5]. Flurbiprofen is a member of the phenyl alkanoic acid derivative of non-steroidal anti-inflammatory drugs (NSAIDs) family. Oral flurbiprofen exhibits low bioavailability since it is a class II drug according to biopharmaceutical classification system, has low aqueous solubility. Therefore, to improve its bioavailability, the drug formulated as a transdermal gel. The absorbed drug appears to be adequate for therapeutic uses in spite of its amount required for therapeutic effect in transdermal drug delivery system is less bioavailable as compared to the oral route of administration [6]. The gel is a solid jelly-like material that can have properties ranging from soft and weak to hard and tough. It is a network of polymer chains that are hydrophilic, sometimes found as a colloidal in which water is the dispersion medium, it can contain more than $90 \%$ water. It is highly absorbed synthetic or natural polymeric networks. It also possesses a degree of flexibility very similar to natural tissue due to their significant water content. Drug penetration via transdermal route can be improved using penetration enhancers [6-8].

Numbers of literature contain reports using different material which used as penetration enhancers. There are different mechanisms for the enhancement of these substances, and they are classified according to their chemical structure. This classification is out of practical assistance since they improve penetration through the skin by different mechanisms that may not be straightforward to illustrate. Depending on the enhancer physicochemical properties, substances which belong to the same group may have different mechanisms of enhancement. Most of the effective enhancers are a surfactant which has a deteriorating effect on the living cell for long-term use. Almond and olive oil are natural oils and have been used as skin penetration enhancers in various concentrations which significantly enhance the drug permeation transdermally $[7,9,10]$. As a gel formulation, drugs can be trapped within polymers network then released by diffusion based on zero order kinetic. The rate of drug release and diffusion kinetics from gel are determined by the drug-polymer interaction, the intrinsic properties of the gel, drug solubility and the amount of entrapped drug [11].

The study aimed to investigate the efficacy and safety of castor oil as a permeation enhancer on the permeability of flurbiprofen from the transdermal gel using Franz cells.

\section{MATERIALS AND METHODS}

\section{Materials}

Flurbiprofen was purchased from FAC limited (India), Carbopol 940 was bought from Sigma Chemicals (USA). Castor oil was provided from Hemani live natural (Pakistan). Triethanolamine (TEA) was purchased from Merck (Germany). Franz cell was bought from SES GmbH (Germany).

\section{Method}

Preparation of flurbiprofen hydrogel

The gel was developed by dispersing carbopol $940(2 \%)$ in a sufficient amount of distilled water and stirred till a homogeneous dispersion obtained. Flurbiprofen (1\%) was dissolved in a suitable volume of $96 \%$ ethanol and sonicated to get a solution. The drug solution was added to carbopol 940 dispersion drop-wise and was stirred continuously. Castor oil was added in different concentrations to 5 different formulas; leaving one without the oil, being the control and the others containing different amount of the enhancer of $1 \%, 2 \%, 3 \%, 4 \%$, and $5 \%$. A solution of triethanolamine (TEA) was added drop-wise (Up to 1\%) for all formulas and mixed. The final volume of the gel was up to $40 \mathrm{ml}$ adding the required volume of distilled water and stirred to get a homogenous gel [10, 12-14]. 


\section{Evaluations of flurbiprofen hydrogel}

\section{Organoleptic characteristics}

They include the products liquefaction, color, phase separation and homogeneity which were investigated by visual inspection at various intervals at $1^{\text {st }}, 2^{\text {nd }}, 5^{\text {th }}, 10^{\text {th }}, 20^{\text {th }}, 30^{\text {th }}$, and $50^{\text {th }} \mathrm{d}$.

\section{Skin irritation test}

It was performed by applying $1 \mathrm{~g}$ of the formula of gel on the hand to a 2 square inch area near the wrist and was observed for any lesions, irritation, stinging or redness, the number of volunteers was ten patients $[10,13]$.

\section{pH changes}

The $\mathrm{pH}$ of different gel formulations was checked using $\mathrm{pH}$ meter Hanna (USA) at $1^{\text {st }}, 3^{\text {rd }}, 7^{\text {th }}, 12^{\text {th }}, 19^{\text {th }}, 21^{\text {th }}, 28^{\text {th }}, 40^{\text {th }}$, and $50^{\text {th }} d$ after formulation.

\section{Drug content}

An amount of $100 \mathrm{mg}$ of the formulated gel for each formula was separately dissolved in $100 \mathrm{ml}$ of phosphate buffer $\mathrm{pH} 7.4$ stirred for sufficient time to get completely soluble and filtered by syringe filter of $0.45 \mathrm{~mm}$ pore size. The concentration of flurbiprofen was measured spectroscopically using the regression equation of the drug calibration curve in 7.4 phosphate buffer at $274 \mathrm{~nm}$ [15].

\section{Viscosity}

The viscosity of the formulated gel was assisted using Brookfield viscometer at $37^{\circ} \mathrm{C}$. The apparatus spindle was rotated $10 \mathrm{rpm}$. The mean of three readings has been calculated to determine gel viscosity.

\section{In vitro drug permeability and release kinetic study}

Castor oil effect as a permeation enhancer on flurbiprofen penetration through the synthetic membrane was studied using Franz diffusion cell. The receptor compartment was filled with phosphate buffer solution of $\mathrm{pH}$ 7.4. A receptor cell volume of $5 \mathrm{ml}$ and the effective diffusional surface area of $0.8 \mathrm{~cm}^{2}$. The membrane was fixed between the donor and receptor compartment of Franz diffusion cell apparatus. A quantity of $1 \mathrm{~g}$ of the prepared gel formulas installed in the donor compartment. The medium was stirred at $100 \mathrm{rpm}$, and the temperature of the cell was maintained at $37{ }^{\circ} \mathrm{C}$. The samples of $2 \mathrm{ml}$ were drawn from the receptor compartment at specified intervals then replaced with an equal volume of the fresh buffer to keep the sink conditions. The flurbiprofen amount in the drawn samples was qualified spectroscopically using the regression equation of the drug calibration curve in 7.4 phosphate buffer at $274 \mathrm{~nm}$ [13]. The drug release mechanism was determined using Korsmeyer Pappas kinetic model. The in vitro flurbiprofen mechanism of release was found outputting the permeation data in the model equation below:

$$
\frac{\mathrm{Mt}}{\mathrm{M} \infty}=\mathrm{K} * \mathrm{t}^{\mathrm{n}}
$$

Where $\mathrm{Mt} / \mathrm{M} \infty$ is the fractional drug release from the gel into the receptor media, $\mathrm{K}$ is a flurbiprofen delivery constant whereas (n) is diffusion coefficient and its value indicates the mechanism of the drug release in the solvent. The (n) value of 0.5 that indicates QuasiFickian diffusion mechanism, while if $(n>0.5)$ then anomalous or non-Fickian diffusion mechanism exists and if it is $(=1)$ then the Zero order release one exists [11].

\section{Flurbiprofen-other additives compatibility study}

The drug and other excipients compatibility were conducted using Fourier-transform infrared spectroscopy (FTIR). The FTIR spectrum of the pure drug was compared with the spectra of the optimum formula physical mixture to identify drug-excipient compatibility.

\section{Statistical analysis}

Statistical analysis was carried out using one-way analysis of variance (ANOVA). The difference is considered statistically significant when $p<0.05$.

\section{RESULTS AND DISCUSSION}

\section{Evaluation of prepared flurbiprofen hydrogel \\ General characteristics of formulated gels}

All characterization properties of the prepared flurbiprofen hydrogel such as the color, liquefaction, phase separation, and skin irritation test have been evaluated. The results indicate good physical stability of the all formulated gels since there were no liquefaction, color change or phase separation along $50 \mathrm{~d}$ from the time of gel formulation. There was no skin irritation in the applied area of the volunteers, and this indicates the formulated gels are suitable for human skin. The gel color was white for all formulations, and that color was stable along the period of evaluation. The drug content of the flubiprofen gel formulas was between $94.7 \% \pm 2.1$ and $98 \% \pm 1.2$ demonstrated a good content uniformity for the prepared formulas [15-19]. The viscosity of the formulas decreased with increasing enhancer concentration. It was between $17850 \mathrm{cP}$ to 15935 cP (table 1) [20].

Table 1: The drug content of the gel formulations of flurbiprofen $1 \%(w / v)$, the results represent mean $\pm \operatorname{SD}(n=3)$

\begin{tabular}{llll}
\hline Formulas & Castor oil & Viscosity (cP) at 10 rpm & Drug content \\
\hline F1 & $0 \%$ & $19850 \pm 45$ & $98 \% \pm 1.2$ \\
F2 & $1 \%$ & $18623 \pm 15$ & $95.1 \% \pm 1.9$ \\
F3 & $2 \%$ & $18173 \pm 19$ & $97 \% \pm 1.5$ \\
F4 & $3 \%$ & $17862 \pm 42$ & $96 \% \pm 1.1$ \\
F5 & $4 \%$ & $17528 \pm 37$ & $94.7 \% \pm 2.1$ \\
F6 & $5 \%$ & $17182 \pm 23$ & $95.4 \% \pm 1.6$ \\
\hline
\end{tabular}

*The gel formulas containing $1 \%$ flurbiprofen, $2 \%$ carpabol 940 , TEA, and the stated concentration of castor oil.

\section{pH changes}

The $\mathrm{pH}$ of gel formulas was measured using $\mathrm{pH}$ meter (fig. 1). All the formulas were safe, stable, and did not irritate since their $\mathrm{pH}$ was within the normal skin pH range (4 to 7 ) and there is no significant difference throughout storage time of the formulas [19].

\section{In vitro drug permeability and release kinetics}

The flurbiprofen release from the gel through the membrane (Franz cell) explained in fig. 2. It is found that the gel formulation without penetration enhancer had the lowest percentage of the drug permeation of $47 \%$ after $24 \mathrm{~h}$. However, adding castor oil to the gel significantly $(\mathrm{P}<0.05)$ improved the drug penetration. The percent of flurbiprofen penetration reached to $79 \%$ adding $1 \%$ enhancer to the gel, and the drug permeation was significantly $(\mathrm{P}<0.05)$ raised with increasing castor oil concentration reaching $81 \%$ from the gel of $2 \%$ castor oil. Moreover, $85 \%, 88 \%$ and the maximum percentage of the release $95 \%$ were obtained by adding $3 \%, 4 \%$, and $5 \%$ of castor oil, respectively.

In comparison with other studies used oils (almond and olive oil) as permeability enhancers, the results showed the same enhancing ability for ketoprofen and flurbiprofen transdermally $[9,10,13]$. That is because of the ability of castor oil to enhance the diffusion of the drug by modifying the barrier characteristics of the membrane and could be the stratum corneum. Carbopol 940 was used in the formulation of the gel to control the release rate of flurbiprofen up to $24 \mathrm{~h}$ since it is a controlling rate polymer $[17,21,22]$. 


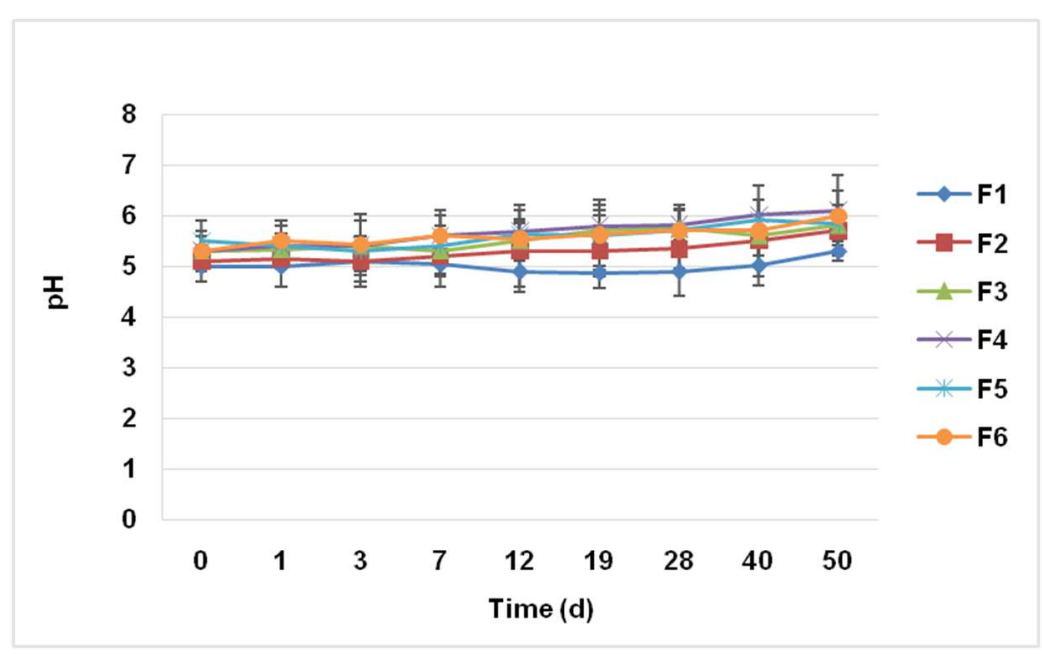

Fig. 1: The $\mathrm{pH}$ value of flurbiprofen formulated gel with time of storage, all the values represent by mean $\mathrm{pH} \pm \mathrm{SD}$, where $\mathrm{F} 1 \mathrm{formula}$ is the gel without castor oil (control) and F2, F3, F4, F5, and F6 containing 1\%, 2\%, 3\%, 4\%, and $5 \%$ castor oil respectively. $(n=3)$

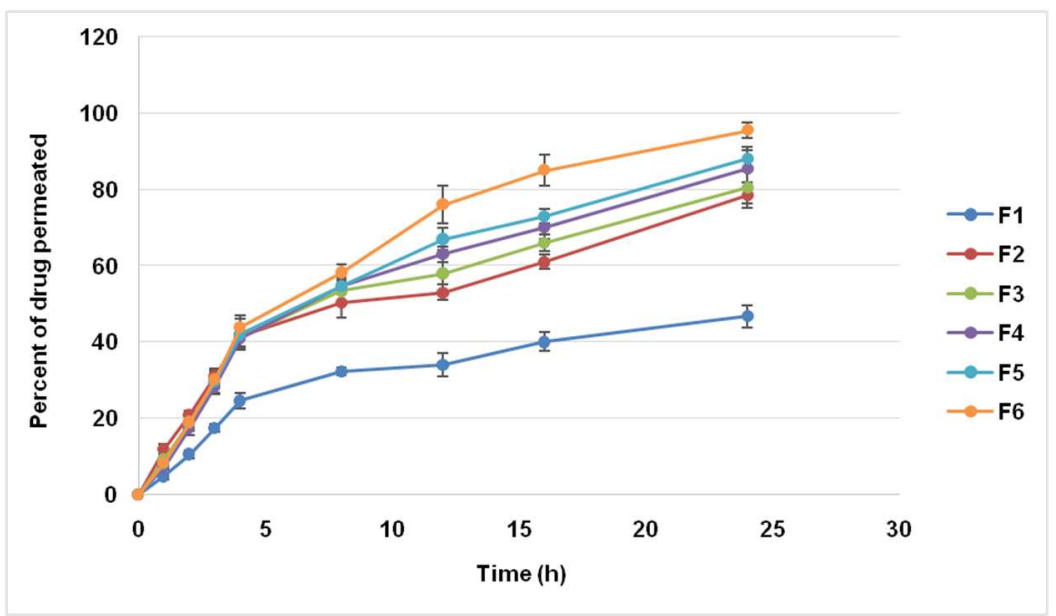

Fig. 2: Percentage of flurbiprofen permeated across synthetic membrane in pH 7.4 buffer, this study was performed using Franz cell, all the values represent by mean percent of the drug permeated \pm SD, where F1 formula is the gel without castor oil (control) and F2, F3, F4, F5, and F6 containing $1 \%, 2 \%, 3 \%, 4 \%$, and $5 \%$ castor oil respectively. $(n=3)$

The release kinetics of the gel was determined by applying Korsmeyer Pappas model on flurbiprofen penetration profiles from the formulated gel. As mentioned above an $(n)$ value in this release kinetic model equation is the way of the drug releasing from the gel across the membrane into the receptor media. The $(n)$ values of the model were $1<n>0.5$ revealing that two mechanisms for the drug release from the gel were involved, which are non-Fickian (anomalous) and super case II transport (table 2) [11, 22, 23].

Table 2: Korsmeyer-peppas kinetic model for flurbiprofen penetration through the synthetic membrane, where the F1 formula is the gel without castor oil (control) and F2, F3, F4, F5, and F6 containing 1\%, $2 \%, 3 \%, 4 \%$, and $5 \%$ castor oil respectively

\begin{tabular}{|c|c|c|c|}
\hline Formulas & $\mathbf{R}^{2}$ & n-value & Type of release \\
\hline F1 & 0.9119 & 0.8314 & Non-Fickian diffusion \\
\hline F2 & 0.9353 & 1.1708 & Super case-II transport \\
\hline F3 & 0.929 & 1.0924 & Super case-II transport \\
\hline $\mathrm{F} 4$ & 0.9226 & 1.0219 & Super case-II transport \\
\hline F5 & 0.9326 & 1.0604 & Super case-II transport \\
\hline F6 & 0.9424 & 1.058 & Super case-II transport \\
\hline
\end{tabular}

\section{Compatibility study}

The FTIR spectra (fig. 3) demonstrated no significant change of pure flurbiprofen peaks and the gel mixture.

Therefore, there was no interaction between the drug and the gel component ingredients. The characterized broad peaks of flurbiprofen at 1656 , and $2934 \mathrm{~cm}^{-1}$ were present because of the drug carbonyl and hydroxyl group stretching. These two fingerprint groups' peaks of the drug had been shown in the gel mixture spectrum. However, the spectrum of the gel mixture shows broad peak 3400 to $1700 \mathrm{~cm}^{-1}$ due to hydrogen bond [24-26]. 

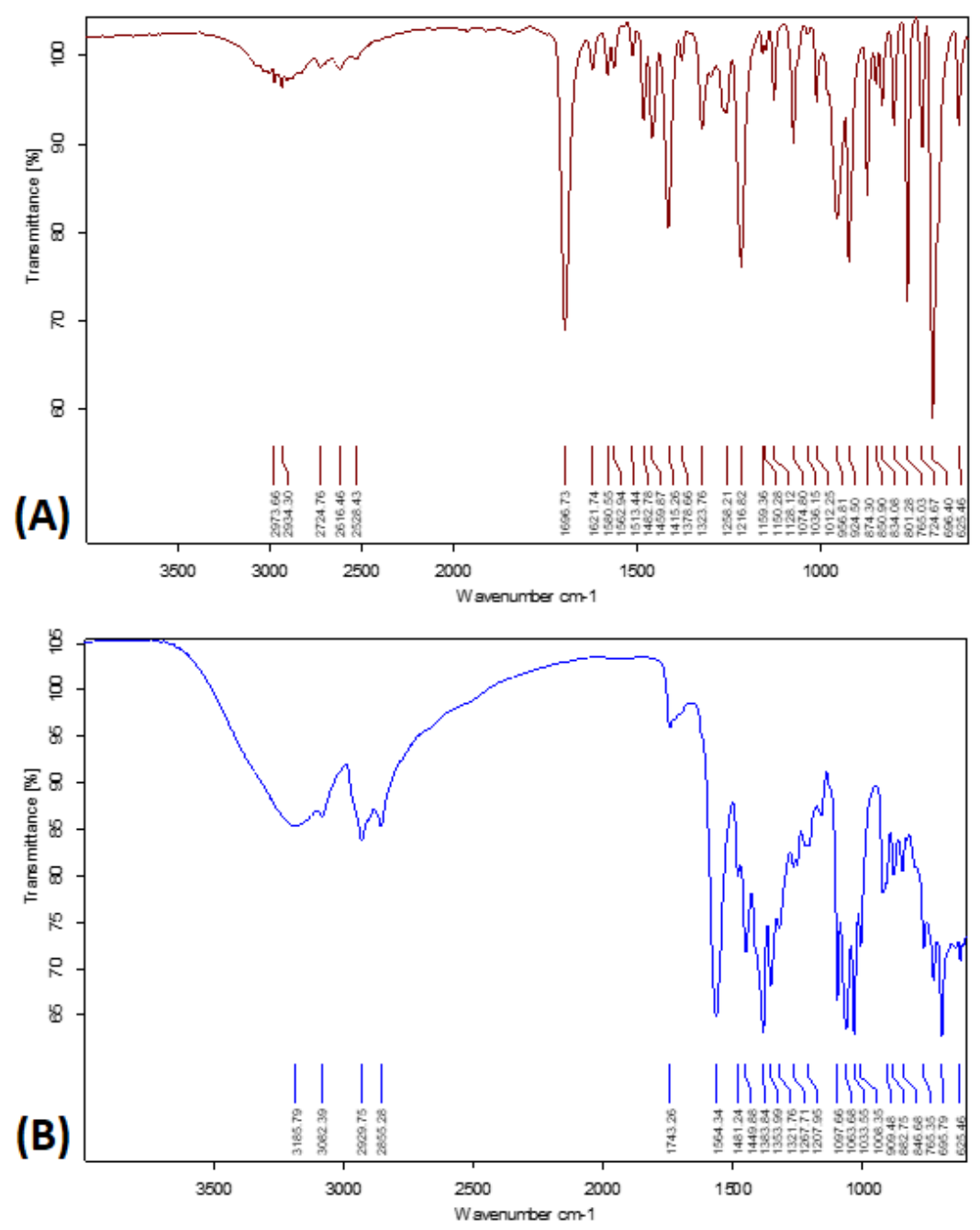

Fig. 3: FTIR spectra of flurbiprofen and the gel formulations additives, where (A) represents pure drug spectrum, while (B) flurbiprofen and gel ingredients mixture

\section{CONCLUSION}

Flurbiprofengel was prepared and evaluated successfully for an in vitro parameters with a good permeation across the synthetic membrane. The results demonstrated that castor oil had an effective enhancement for permeation of flurbiprofen. The gel formulations with the higher concentration of the oil were significantly $(\mathrm{P}<0.05)$ enhanced penetration of the drug through the membrane which indicates that there are two release mechanisms for flurbiprofen from the gel, including non-Fickian and super case II transport.

\section{AUTHORS CONTRIBUTIONS}

All the authors contributed equally.

\section{CONFLICT OF INTERESTS}

\section{Declared none}

\section{REFERENCES}

1. Finnin BC, Morgan TM. Transdermal penetration enhancers: applications, limitations and potential. J Pharm Sci 1999;88:955-8.

2. Hirva S, Jenisha P. Bicelle: a lipid nanostructure for transdermal delivery. J Crit Rev 2016;3:17-22.

3. Keleb E, Sharma RK, Mosa EB, Aljahwi AZ. Transdermal drug delivery system-designand evaluation. Int J Adv Pharm Sci 2010;1:201-11.
4. Bavaskar K, Jain A, Patil M, Kalamkar R. The impact of penetration enhancers on transdermal drug delivery system: physical and chemical approach. Int J Pharm Res Rev 2015;4:14-24.

5. Biswas GR, Majee SB, Roy A. Combination of synthetic and natural polymers in hydrogel: an impact on drug permeation. J Appl Pharm Sci 2016;6:158-64.

6. Li DX, Han MJ, Balakrishnan P, Yan YD, Oh DH. Enhanced oral bioavailability of flurbiprofen by combined use of micelle solution and inclusion compound. Arch Pharm Rev 2010;33:95-101.

7. Syed NHS, Mahboob R, Muhammad FA. Study of percutaneous absorption of diclofenac diethylamine in the presence of cetrimide through hairless rabbit skin. J Res Sci 2006;17:45-51.

8. Rambharose S, Kalhapure RS, Jadhav M, Govender T. Exploring unsaturated fatty acid cholesteryl esters as transdermal permeation enhancers. Drug Delivery Transl Res 2017;7:333-45.

9. Hussain A, Khan GM, Shah SU, Rahim N. Development of a novel ketoprofen transdermal patch: effect of almond oil as penetration enhancer on in vivo and ex-vivo penetration of ketoprofen through rabbit skin. Pak J Pharm Sci 2012;25:227-32.

10. Hussain A, Khan GM, Jan SU, Shah S, Shah K, Akhlaq M, et al. Effect of olive oil on the transdermal penetration of flurbiprofen from topical gel as an enhancer. Pak J Pharm Sci 2012;25:365-9. 
11. Dash S, Murthy PN, Nath L, Chowdhury P. Kinetic modelling on drug release from controlled drug delivery systems. Acta Pol Pharm 2010;67:217-23.

12. Shah KP, Srivastava RS. Evaluation of anti-oxidant and antiacne activities (in vitro) of the formulated herbal gel. Int J Curr Pharm Res 2015;7:47-50.

13. AL Haydar M. Enhancement effect of almond oil on the transdermal penetration of flurbiprofen topical gel. J Kerbala University 2015;13:156-63.

14. Verma A, Singh S, Kaur R, Jain UK. Formulation and evaluation of clobetasol propionate gel. Asian J Pharm Clin Res 2013;6:15-8.

15. The United State Pharmacopeia (USP), 30, NF28, USA: The United State Pharmacopia Convention Inc; 2010.

16. Lambers H, Piessens S, Bloem A, Pronk H, Finkel P. Natural skin surface $\mathrm{pH}$ is on average below 5 , which is beneficial for its resident flora. Int J Cosmet Sci 2006;28:359-70.

17. Fox LT, Gerber M, Plessis JD, Hamman JH. Transdermal drug delivery enhancement by compounds of natural origin. Molecules 2011;16:10507-40.

18. Helal DA, El-Rhman DA, Abdel-Halim SA, El-Nabarawi MA. Formulation and evaluation of fluconazole topical gel. Int J Pharm Pharm Sci 2012;4:176-83.

19. Ariyana A, Sinurat D, Ervina I, Bangun H. Formulation and in vitro evaluation of alginate based metronidazole periodontal gel. Asian J Pharm Clin Res 2014;7:223-7.
20. Shukr M, Metwally GF. Evaluation of topical gel bases formulated with various essential oils for antibacterial activity against methicillin-resistant Staphylococcus aureus. Trop J Pharm Res 2013;12:877-84.

21. Jafari M, Kaffashi B. Mathematical kinetic modeling on isoniazid release from dex-HEMA-PNIPA Am Nanogels. Nanomed Res J 2016;1:90-6.

22. Marwah H, Garg T, Goyal AK, Rath G. Permeation enhancer strategies in transdermal drug delivery. Drug Delivery 2016;23:564-78.

23. Ramakrishna S, Mihira V, Tabitha K. Design and evaluation of drug release kinetics of diltiazem hydrochloride sustained release tablets. Int J Med Pharm Sci 2011;1:1-13.

24. Lakshmi Radhika G, Mahanthesha MK, Chinna Devi G. Formulation and in vitro evaluation of sustained release matrix tablets of flurbiprofen using hydroxypropyl methylcellulose. Int J Adv Res 2013;1:624-30.

25. Sohail MF, Akhtar Shah P, Tariq I, Saeedul-Hassan A, Amin U, Raza $\mathrm{S}$, et al. Development and in vitro evaluation of flurbiprofen microcapsules prepared by a modified solvent evaporation technique. Trop J Pharm Res 2014;13:1031-8.

26. Najmuddin M, Patel V, Ahmed A, Shelar S, Khan T. Preparation and evaluation of flurbiprofen microcapsule for colonic drug delivery system. Int J Pharm Pharm Sci 2010; 2:83-7. 